\title{
Dimensions of Internet Use: Amount, Variety and Types
}

\author{
Grant Blank and Darja Groselj \\ Oxford Internet Institute \\ University of Oxford
}

1 St Giles

Oxford OX2 3JS

United Kingdom

grant.blank@oii.ox.ac.uk and darja.groseli@oii.ox.ac.uk

Grant Blank is the Survey Research Fellow at the Oxford Internet Institute, University of Oxford. He is editor (with Nigel Fielding and Raymond Lee) of the Handbook of Online Research Methods and numerous other publications on the Internet. His special interests are the social impact of computers and the Internet, statistical and qualitative methods, and cultural sociology.

Darja Groselj is a doctoral candidate at the Oxford Internet Institute, University of Oxford, UK. Her research examines how various characteristics of the individuals' Internet use environment shape their Internet use patterns. Darja is currently also working as a Survey Research Assistant for the Oxford Internet Surveys (OxIS) project. 


\begin{abstract}
We examine the dimensions of Internet use based on a representative sample of the population of the United Kingdom, making three important contributions. First, we clarify theoretical dimensions of Internet use that have been conflated in prior work. We argue that the property space of Internet use has three main dimensions: amount of use, variety of different uses, and types of use. Second, the Oxford Internet Survey 2011 dataset contains a comprehensive set of 48 activities ranging from email to online banking to gambling. Using principal components analysis we identify ten distinctive types of Internet activities. This is the first typology of Internet uses to be based on such a comprehensive set of activities. We use regression analyses to validate the three dimensions and to identify the characteristics of the users of each type. Each type has a distinctive and different kind of user. The Internet is an extremely diverse medium. We cannot discuss "Internet use" as a general phenomenon; instead researchers must specify what kind of use they examine.
\end{abstract}

Keywords: Internet use; typology; principal components analysis; amount; variety; types; Oxford Internet Survey; OxIS 


\section{Dimensions of Internet Use: Amount, Variety and Types}

In 2011 73\% of the British population were online (Dutton \& Blank, 2011). However, online activities are extremely diverse, ranging from sending emails to gambling to selling products, to name only a few. The diversity of uses is related to the interactive nature of the Internet as a medium where users-audiences-make active decisions about how to engage with the breadth of possible uses of the Internet (Ruggiero, 2000). On the one hand, this poses a challenge to researchers-how to capture the diversity of Internet uses with, for example, a survey instrument where each additional item is costly. On the other hand, too much detail makes it harder to detect regular patterns in Internet use.

These issues call for a comprehensive study into the diverse uses of the Internet with the goal of reducing the plethora of Internet activities to a smaller number of internally consistent and meaningful categories. A set of Internet use categories is valuable for two reasons. It will help us more clearly determine where Internet use has the largest impact on people's everyday lives. Second, it is a starting point to help identify the social locations and characteristics of people who differ along various dimensions of Internet use.

Previous researchers have recognised this and several typologies of Internet users have been constructed (e.g. Brandtzæg, 2010; Horrigan, 2007; Livingstone \& Helsper, 2007). Yet, these typologies have often resulted in conceptually incoherent categories. For example, Brandtzæg synthesizes results from 22 studies and proposes eight user types. Among the eight are two categories that distinguish between sporadic users and entertainment users. However, 'sporadics' is a category related to amount of use whereas entertainment use is a certain type of use. Brandtzæg's typology does not account for people who may be entertainment users of different frequencies (including sporadic) and, conversely, that sporadic users may engage in many different activities (some of which might be entertainment-related). Similar comments apply to Brandtzæg's other six categories, as well as most other existing typologies. Such typologies conflate elements that are conceptually separate dimensions. There seems to be theoretical confusion about the logical dimensions of Internet use across the literature. We suggest that dimensions of Internet use must first be specified theoretically and then all possible variations and combinations can be spelled out in the categories of a typology. Empirical work has to follow the theory. In the following paper we first describe three dimensions along which Internet use will vary in theory. These are amount of use, variety of use, and types of use. Second, we review how previous research has handled these dimensions. Third, using a representative data set, we describe these dimensions in Britain, particularly focusing on the different types of Internet use. Finally, we validate that these are unique dimensions by showing that each dimension is characterized by users with distinctive demographic characteristics.

\section{THEORETICAL FRAMEWORK}

Our thinking about dimensions of Internet use is grounded in Barton's (1955) idea of property space. Barton describes a property space as a combination of properties along which a phenomenon is characterised. Each property represents a logically independent dimension, which means that individuals can be located on any one dimension without regard to their location on other dimensions. For example, people can be characterized by their scores on mathematical and linguistic ability tests. These two scores locate them in a "property space" with the two dimensions of mathematical and linguistic ability. This can also be thought of as a mapping of each individual onto a coordinate system along pre-defined axes.

We can design a property space of Internet use using this approach. We identify properties which describe meaningful patterns of use. These properties constitute dimensions which construct a space of Internet use where any individual can be located based on their "score" on each

Blank \& Groselj Dimensions of Internet Use 
dimension. Such conceptualization of Internet use prevents us from arbitrarily excluding some combinations of dimensions of Internet use, a common weakness of previous studies (see next section). However, in order to do so we also need to identify the boundaries of variation of each dimension.

Drawing on our conceptual thinking about the Internet as well as a critical assessment of previous typologies presented below we identify three properties of Internet use. The goal is to identify broad dimensions along which Internet use can vary, and that can be used to locate any user. The properties we propose are (1) amount, (2) variety, and (3) type of Internet use.

We call the first dimension the amount of Internet use. This is a continuous variable measuring the frequency of Internet use in day-to-day life, not the length of time someone has been using the Internet. Amount of use (in previous research often called "frequency of use") is a relevant property since Internet users can vary extensively in how much time they spend online-some people use it for many hours each day, others only once a week.

The second dimension is variety of Internet use. This is an interval variable measuring the number of different activities that individuals undertake online (in previous research some authors refer to it as "breadth of use"). Variety is a separate property of Internet use, since users may undertake one or several Internet uses. Variety is logically distinct from amount of use. For example, someone can log onto Facebook in the morning and use it for the entire day. We would describe their amount of use as very high, but, since they only did one activity, their variety of use is low.

The third dimension is type of Internet use. This is a series of nominal variables describing different activities people engage in online. Activities include anything from sending emails to investing in stock to making travel reservations to gambling. These activities are discrete categories and, since people can do many different things, individuals may be located in more than one category.

Types of use need to be defined on a conceptual level. This means it is important to move beyond the detail of specific, individual activities (e.g. using email, watching videos, ordering groceries) to more abstract categories. This gives us a relatively limited number of conceptual units to deal with in the property space. Thus, one aim of the data analysis is to identify a relatively small, manageable set of internally consistent types of Internet use. Type of use is logically distinct from either amount or variety of use. For example, one person could be an intensive gambler and email user while another person is an intensive user of social network sites and email. In terms of our three dimensions, both would (1) score high on amount of use and have (2) the same variety of use-2 activities - but have (3) a different combination of use types. Any combination of amount, variety and types is possible. The point of the property space is that people can vary independently along all three of these dimensions.

The value of defining a property space of Internet use for future research is (at least) threefold. First, by identifying meaningful dimensions of Internet use beforehand we avoid the confusion and inconsistency in describing Internet users. Second, by drawing on such a theoretical framework we will not overlook empirically existing possibilities of Internet use, which some previous typologies do. Third, by allowing independent variation among the dimensions, the proposed framework is more flexible than prior work. Each dimension can vary independently. This can be valuable in comparative research, either cross-national or longitudinal, where the exact conjuncture of empirically existing users may vary in different locations or across time. For example, in crossnational research, some countries could have different types of use, while others could share the same types but vary in their variety. This approach allows more precise identification of where the differences are located. A similar argument applies as Internet use changes longitudinally over time. In the next section of the paper we review previous research on dimensions of Internet use. 


\section{DIMENSIONS OF INTERNET USE IN PREVIOUS RESEARCH}

Table 1 summarizes previous studies that created a typology of Internet users or uses. The table includes only those studies based on a sample representative of a population. We acknowledge the contributions that papers based on convenience samples make to our understanding of Internet use. Yet, here we review only studies which used data representing a population because we are interested in Internet use without the unknown biases of nonrepresentative samples. ${ }^{1}$ We exclude papers that create typologies as part of a discussion of the digital divide or another topic (e.g. van Deursen \& van Dijk, 2013). Their primary focus is not on the characteristics or quality of the typology but on their substantive topic. The purpose of this review is identifying dimensions of Internet use.

\footnotetext{
${ }^{1}$ We also excluded studies that contain the Internet in a more general typology of media use, and market reports or attempts to segment Internet users for marketing purposes.
} 
Table 1: Summary of previous studies

\begin{tabular}{|c|c|c|c|c|}
\hline Reference & Population & Method & Typology & $\begin{array}{l}\text { Named } \\
\text { dimensions }\end{array}$ \\
\hline $\begin{array}{l}\text { Howard, } \\
\text { Rainie, and } \\
\text { Jones } \\
\text { (2001) }\end{array}$ & $\begin{array}{l}\text { USA } \\
(N=10,253)\end{array}$ & $\begin{array}{l}\text { Descriptive } \\
\text { statistics } \\
28 \text { use vars }\end{array}$ & $\begin{array}{l}\text { Netizens: Daily use, } 3+\text { years } \\
\text { Utilitarians: Daily use; } 3+\text { years; less intense } \\
\text { Experimenters: Daily use; } 1-3 \text { years } \\
\text { Newcomers: Use } 1 \text { year or less }\end{array}$ & $\begin{array}{l}\text { Frequency of } \\
\text { logging on } \\
\text { Years of } \\
\text { Internet use }\end{array}$ \\
\hline $\begin{array}{l}\text { Selwyn, } \\
\text { Gorard, and } \\
\text { Furlong } \\
(2005)\end{array}$ & $\begin{array}{l}4 \text { UK regions } \\
(N=1,001)\end{array}$ & $\begin{array}{l}\text { Descriptive } \\
\text { statistics } \\
\text { \# use vars } \\
\text { unknown }\end{array}$ & $\begin{array}{l}\text { Broad frequent users: Frequent use, 3+ purposes } \\
\text { Narrow frequent users: Frequent use, 1-2 purposes } \\
\text { Occasional users: Occasional use } \\
\text { Non-users: Not used in past } 12 \text { months }\end{array}$ & $\begin{array}{l}\text { Frequency of } \\
\text { Internet use } \\
\text { Range of use }\end{array}$ \\
\hline $\begin{array}{l}\text { Ortega } \\
\text { Egea, Recio } \\
\text { Menéndez, } \\
\text { and Román } \\
\text { González, } \\
(2007)\end{array}$ & $\begin{array}{l}15 \mathrm{EU} \\
\text { countries } \\
(\mathrm{N}=30,336)\end{array}$ & $\begin{array}{l}\text { Two-step } \\
\text { cluster } \\
\text { analysis } \\
23 \text { use vars }\end{array}$ & $\begin{array}{l}\text { Laggards: Occasional use; don't use eGovernment } \\
\text { Confused and Adverse: Intermediate, high } \\
\text { variability of use; don't shop } \\
\text { Advanced Users: Frequent users; eGovernment, } \\
\text { shopping } \\
\text { Followers: Frequent use; eGovernment, don't shop }\end{array}$ & $\begin{array}{l}\text { Frequency of } \\
\text { access } \\
\text { Degree of } \\
\text { innovative- } \\
\text { ness }\end{array}$ \\
\hline $\begin{array}{l}\text { Horrigan } \\
(2007)\end{array}$ & $\begin{array}{l}\text { USA } \\
(N=4,001)\end{array}$ & $\begin{array}{l}\text { Cluster } \\
\text { analysis } \\
8 \text { assets } \\
\text { vars; } \\
1 \text { connection } \\
\text { type var; } \\
17 \text { ICT use } \\
\text { vars; } \\
12 \text { attitudes } \\
\text { vars }\end{array}$ & $\begin{array}{l}\text { Omnivores: Own many ICTs, use Web } 2.0 \\
\text { Connectors: Frequent use; ICTs to connect to } \\
\text { people \& content; satisfied } \\
\text { Lacklustre Veterans: Frequent use; not thrilled with } \\
\text { ICT-enabled connectivity } \\
\text { Productivity Enhancers: Strong positive views that } \\
\text { technology helps productivity } \\
\text { Mobile Centrics: Use mobile phones; like how ICTs } \\
\text { connect them } \\
\text { Connected but Hassled: Find connectivity intrusive } \\
\text { and information a burden } \\
\text { Inexperienced Experimenters: Occasional use; } \\
\text { might do more if had more experience } \\
\text { Light but Satisfied: Have some ICTs, but do not play } \\
\text { a central role in daily life } \\
\text { Indifferents: Use ICTs intermittently, find } \\
\text { connectivity annoying. } \\
\text { Off the Network: Have neither a cell phone nor } \\
\text { Internet connection }\end{array}$ & $\begin{array}{l}\text { Assets } \\
\text { Actions } \\
\text { Attitudes }\end{array}$ \\
\hline $\begin{array}{l}\text { Heim and } \\
\text { Brandtzæg } \\
(2007)\end{array}$ & $\begin{array}{l}\text { Austria, } \\
\text { Germany } \\
\text { and Norway } \\
(\mathrm{N}=24,468)\end{array}$ & $\begin{array}{l}48 \text { to } 73 \text { vars } \\
\text { to generate } \\
12 \text { use-and- } \\
\text { skills vars } \\
\text { included in } \\
\text { the analysis }\end{array}$ & $\begin{array}{l}\text { Non-users: Don't use ICTs } \\
\text { Average users: Occasional use; low skills } \\
\text { Instrumental users: Frequent use; for utility or } \\
\text { information acquisition } \\
\text { Entertainment users: Frequent use; for } \\
\text { entertainment activities } \\
\text { Advanced users: Most frequent use; for many } \\
\text { different purposes }\end{array}$ & $\begin{array}{l}\text { ICT usage } \\
\text { ICTs }\end{array}$ \\
\hline $\begin{array}{l}\text { Livingstone } \\
\text { and Helsper } \\
\text { (2007) }\end{array}$ & $\begin{array}{l}\text { UK; children } \\
(\mathrm{N}=1,511)\end{array}$ & $\begin{array}{l}\text { Descriptive } \\
\text { statistics } \\
15 \text { use vars }\end{array}$ & $\begin{array}{l}\text { Basic Users: } 1-3 \text { activities; esp. information-seeking } \\
\text { Moderate users: } 4-5 \text { activities; information, } \\
\text { communication, entertainment } \\
\text { Broad users: } 6-7 \text { activities; peer-to-peer activities } \\
\text { All Rounders: } 8+\text { activities; wide range of uses }\end{array}$ & $\begin{array}{l}\text { Frequency } \\
\text { Breadth }\end{array}$ \\
\hline
\end{tabular}




\begin{tabular}{|c|c|c|c|c|}
\hline Reference & Population & Method & Typology & $\begin{array}{l}\text { Named } \\
\text { dimensions }\end{array}$ \\
\hline $\begin{array}{l}\text { Brandtzæg } \\
\text { (2010) }\end{array}$ & $\begin{array}{l}\text { Literature } \\
\text { review }\end{array}$ & $\begin{array}{l}\text { Does not } \\
\text { analyze data }\end{array}$ & $\begin{array}{l}\text { Non-users: No media use } \\
\text { Sporadics: Low use and variety; no particular } \\
\text { activity } \\
\text { Debaters: Medium use and variety; discussion and } \\
\text { information activities } \\
\text { Entertainment users: Medium use and variety; } \\
\text { gaming, videos, UGC, shopping } \\
\text { Socializers: Medium use and variety; socialising, } \\
\text { keeping in touch } \\
\text { Lurkers: Medium use; low variety; lurking, time- } \\
\text { killing } \\
\text { Instrumental users: Medium use and variety; } \\
\text { information, work-related purposes } \\
\text { Advanced users: High use and variety; all activities } \\
\text { (games, e-government, shopping, etc.) }\end{array}$ & $\begin{array}{l}\text { Frequency } \\
\text { Variety } \\
\text { Content/activ } \\
\text { ity } \\
\text { preference } \\
\text { Media } \\
\text { platform/ser } \\
\text { vice }\end{array}$ \\
\hline $\begin{array}{l}\text { Brandtzæg, } \\
\text { Heim, and } \\
\text { Karahasa- } \\
\text { nović (2011) }\end{array}$ & $\begin{array}{l}\text { Norway, } \\
\text { Sweden, } \\
\text { Austria, UK, } \\
\text { Spain } \\
(\mathrm{N}=12,666)\end{array}$ & $\begin{array}{l}\text { Cluster } \\
\text { analysis } \\
23 \text { use vars }\end{array}$ & $\begin{array}{l}\text { Non-users: Don't use the Internet } \\
\text { Sporadic users: Occasional use of email and some } \\
\text { specific tasks } \\
\text { Instrumental users: Goal-oriented activities } \\
\text { (information search, banking, commerce) } \\
\text { Entertainment users: Internet radio, TV, music, } \\
\text { chat, downloading games } \\
\text { Advanced users: Varied and broad Internet use }\end{array}$ & $\begin{array}{l}\text { Frequency } \\
\text { Variety } \\
\text { Content } \\
\text { preferences }\end{array}$ \\
\hline $\begin{array}{l}\text { Eynon and } \\
\text { Malmberg } \\
\text { (2011) }\end{array}$ & $\begin{array}{l}\text { UK; young } \\
\text { people } \\
(\mathrm{N}=804)\end{array}$ & $\begin{array}{l}\text { Latent } \\
\text { profile } \\
\text { analysis } \\
21 \text { use vars; } \\
\text { predefined } \\
\text { uses }\end{array}$ & $\begin{array}{l}\text { Peripherals: Low levels of all types of uses } \\
\text { Normatives: Average on information seeking, } \\
\text { communication and entertainment } \\
\text { All-rounders: Above average levels of use of all } \\
\text { types } \\
\text { Active Participators: Most frequent level of use of } \\
\text { all uses; heavy in participating online }\end{array}$ & $\begin{array}{l}\text { Intensity of } \\
\text { use } \\
\text { Activity }\end{array}$ \\
\hline $\begin{array}{l}\text { Holmes } \\
(2011)\end{array}$ & $\begin{array}{l}\text { UK; children } \\
(\mathrm{N}=561)\end{array}$ & $\begin{array}{l}\text { Latent class } \\
\text { analysis } \\
4 \text { use vars }\end{array}$ & $\begin{array}{l}\text { Information focus: Weekly use; schoolwork, } \\
\text { information search. } \\
\text { Recreational focus: Weekly use; IM \& online music; } \\
\text { informational activities } \\
\text { Low users: Use for school, 1-2 activities weekly }\end{array}$ & $\begin{array}{l}\text { Engagement/ } \\
\text { frequency } \\
\text { Activity }\end{array}$ \\
\hline
\end{tabular}

Overall, amount, variety and types of Internet use are the most common dimensions identified in previous research (not usually using these names, see Table 1). The most commonly used dimension is amount of Internet use, measured either as a frequency of going online on a Likert-type scale (Brandtzæg et al., 2011; Howard et al., 2001; Livingstone \& Helsper, 2007; Selwyn et al., 2005), as a frequency of engagement in different online activities (Eynon \& Malmberg, 2011; Holmes, 2011; Horrigan, 2007; Ortega Egea et al., 2007), or as total years of Internet use (Horrigan, 2007; Howard et al., 2001). This is often conflated with either variety or one or more categories containing types of use. For example, Holmes' (2011) category "recreational focus" combines both a frequency component ("weekly use") and two types of use ("informational activities" and "IM and online music"). His scheme has no place, for example, for people who use the Internet less than weekly and also use it for "IM and online music". In general, these typologies share similar shortcomings: by conflating amount or variety with types of use, they cannot capture the full range of Internet use. 
There is little theoretical discussion of appropriate dimensions of Internet use in previous literature. Brandtzæg (2010) is a notable exception calling for a multidimensional view (as also advocated in the digital divide literature, e.g. van Deursen \& van Dijk, 2013; Zillien \& Hargittai, 2009). Brandtzæg's literature review identifies four dimensions used in previous literature: frequency of use, variety of use, content preferences and media platform. ${ }^{2}$ Brandtzæg (2010) finds eight user types in previous literature and Brandtzæg et al.'s (2011) cluster analysis of users (cases) results in five user categories. Taking the 2011 results as an example, two categories of users are primarily described by amount of use (non-users and sporadic users), two categories are described by their typical activities (entertainment users and instrumental users) whereas the final category is characterized by variety of use (advanced users). This is an unwieldy set of categories because it combines amount (e.g. "sporadic") and type of use (e.g. "entertainment") into a single dimension. These categories are not mutually exclusive and a single user, like a sporadic entertainment user, fits into two categories. This is a strong clue that there are separate dimensions. The source of the problem is the variables in the cluster analysis. Cluster analysis results are totally dependent on the variables included, and Brandtzaeg et al. (2011, Table 3) have included variables measuring all three dimensions of use. This initial theoretical confusion results in confused output. If the cluster analysis results are to be meaningful, the analysis must begin with a theoretically consistent set of variables. Despite his promising start, both of Brandtzæg's typologies end up with exactly the same weakness as other studies that collapse several theoretical dimensions of Internet use in a single empirical dimension with multiple categories (e.g. Eynon \& Malmberg, 2011; Heim \& Brandtzæg, 2007; Horrigan, 2007; Howard et al., 2001; Ortega Egea et al., 2007; Selwyn et al., 2005). ${ }^{3}$

The analysis of the literature summarized in Table 1 and beyond leads us to conclude that there is a great deal of confusion about the dimensions of Internet use. Existing typologies are inconsistent, rigid and primarily data-driven. By contrast, we argue that before engaging with the data, the nature of Internet use has to be theorized along meaningful dimensions. These dimensions should have three characteristics: They should embrace a logic of how Internet use can reasonably vary, they should be separate and the boundaries of their variation should be defined. In essence, this paper takes a step back to the discussion of important dimensions of Internet use with an aim of helping future research avoid conflating theoretically distinct aspects of Internet use. Below we move beyond theorizing the property space of Internet use to operationalize and analyse each of the three proposed dimensions-amount, variety and type of use-empirically.

\section{DATA AND MEASUREMENT}

The Oxford Internet Surveys (OxIS) collect data on British Internet users and non-users. Conducted biennially since 2003, the surveys are nationally representative random samples of over 2,000 individuals aged 14 and older in England, Scotland, and Wales. Interviews are conducted face-toface by an independent survey research company. The analyses below are based on the $73 \%$ of the respondents who were Internet users in 2011, $N=1,498$.

OxIS contains measures of all three dimensions of Internet use. The analysis is based on 48 variables asking about Internet activities, see Table 2 . For the first dimension, we want to measure

\footnotetext{
${ }^{2}$ Note, however, that Brandtzæg (2010) is not consistent in the number of identified dimensionshe proposes 3 separate dimensions on pages 940 and 954; and 4 separate dimensions on page 951 and in Table 6.

${ }^{3}$ We identified only one study that develops a typology of Internet users based on one conceptual dimension: Livingstone and Helsper (2007).
} 
total amount of use. Each variable is identically measured on a 6-point Likert scale, asking respondents how often they do the activity where "never" = 0 and "more than once per day" $=5$. This supplies a measure of how much any respondent does each activity. The sum of the variables measures the total amount of Internet use. Our variable is continuous, with a theoretical range from zero to 240 . The second dimension is the variety of Internet use. Variety is measured by the count of the number of activities that a respondent does more than never, with a theoretical range from zero to 48 . The third dimension is based on extracting types of use from the individual activities listed in Table 2.

We also use standard demographic variables. We use four education categories: no degree, secondary, further, and university education. Race is coded as white versus non-white. Place is coded as urban versus rural. Lifestage is a four-category variable: students, employed, unemployed and retired. Marital status has five categories: single, married, living with partner, divorced, widowed. We also include gender and age. 
Table 2: Internet Activity Variables

\begin{tabular}{|c|c|c|c|}
\hline Type & Name & & Item \\
\hline Entertain & Movies & * & How often do you: Watch movies or films online? \\
\hline Entertain & TV & $*$ & How often do you: Watch TV programs on the Internet? \\
\hline Entertain & Dl music & $*$ & How often do you: Download music? \\
\hline Entertain & Listen music & * & How often do you: Listen to music online? \\
\hline Entertain & Videos & * & How often do you: Watch videos online? \\
\hline Entertain & Dl video & $*$ & How often do you: Download videos? \\
\hline Commerce & Buy & $*$ & How often do you: Buy a product online? \\
\hline Commerce & Travel res & $*$ & How often do you: Make travel reservations/bookings? \\
\hline Commerce & Pay bills & $*$ & How often do you: Pay bills? \\
\hline Commerce & Banking & $*$ & How often do you: Use your bank's online services? \\
\hline Commerce & Compare & * & How often do you: Compare products and prices? \\
\hline Commerce & Food & $*$ & How often do you: Order groceries or food online? \\
\hline Commerce & Selling & $*$ & How often do you: Sell things online? \\
\hline Info seek & Facts & * & How often do you: Find or check a fact? \\
\hline Info seek & Definitions & $*$ & How often do you: Look up a definition of a word \\
\hline Info seek & Topics & $*$ & How often do you: Investigate topics of personal interest \\
\hline Socialise & IM & $*$ & How often do you: Do instant messaging? \\
\hline Socialise & Chat & $*$ & How often do you: Participate in chat rooms? \\
\hline Socialise & Photos & $*$ & How often do you: Post pictures or photos on the Internet? \\
\hline Socialise & SNS & $*$ & How often do you: Check or update your profile on a social networking \\
\hline Email & Email & $*$ & How often do you: Check your email? \\
\hline Email & Attach & $*$ & How often do you: Send attachments with your email? \\
\hline Email & List & $*$ & How often do you: Use a distribution list for email? \\
\hline Blog & Phone & $*$ & How often do you: Make or receive phone calls over the Internet? \\
\hline Blog & Read blog & $*$ & How often do you: Read a web-log or blog? \\
\hline Blog & Write blog & $*$ & How often do you: Write a web-log or blog? \\
\hline Blog & Website & $*$ & How often do you: Maintain a personal website? \\
\hline Production & Ul video & $*$ & How often do you: Post a video or video clip? \\
\hline Production & Ul creative & $*$ & How often do you: Post writing, stories, poetry or other 'creative' work \\
\hline Production & Jokes & $*$ & How often do you: Get jokes, cartoons or other humorous content \\
\hline Production & Ul files & $*$ & How often do you: Upload videos or music files? \\
\hline Cl Media & News & $*$ & How often do you: Look for news - local, national, international \\
\hline Cl Media & Events & $*$ & How often do you: Get information about local events? \\
\hline Cl Media & Sports & $*$ & How often do you: Look for sports information? \\
\hline Cl Media & Travel plan & $*$ & How often do you: Make travel plans? \\
\hline Schl-work & Seek job & $*$ & How often do you: Look for jobs, work? \\
\hline Schl-work & School & $*$ & How often do you: Get information for school \\
\hline Schl-work & Work & $*$ & How often do you: Get information for work \\
\hline Schl-work & Distance $\ln$ & * & How often do you: Online distance learning for academic degree/job training \\
\hline Vice & Gambling & $*$ & How often do you: Bet, gamble or enter sweepstakes? \\
\hline \multirow[t]{8}{*}{ Vice } & Adult & $*$ & How often do you: Look at 'adult' sites with sexual content? \\
\hline & Board & & How often do you: Post messages on discussion or message boards? \\
\hline & Games & & How often do you: Play games? \\
\hline & Invest & & How often do you: Invest in stocks/bonds/funds? \\
\hline & NewsPap & & How often do you: Read any newspaper or news service on the Internet \\
\hline & Health & & How often do you: Find information about health or medical care \\
\hline & Google & & How often do you: Find information about about other people? \\
\hline & Location & & How often do you: Find location of a house, office, store, restaurant? \\
\hline
\end{tabular}

Notes: Total: 48 variables; * = Included in principal components analysis (41 variables)

“Cl” = Classic mass media; "Dl” = Download; "Ul” = Upload; “SNS” = Social network site; "IM” = Instant messaging; "In” = learning 


\section{RESULTS}

The distribution of variety of use is plotted in Figure 1. The average Internet user reports doing 25 different activities, a surprisingly large number. The actual mean is 24.6 and the median is 25. A major point that the histogram illustrates is that the distribution shows no evidence of any gaps or breaks that could support splitting it into the three or four categories typical of some other studies of Internet use.

Figure 1: Variety of Internet Use

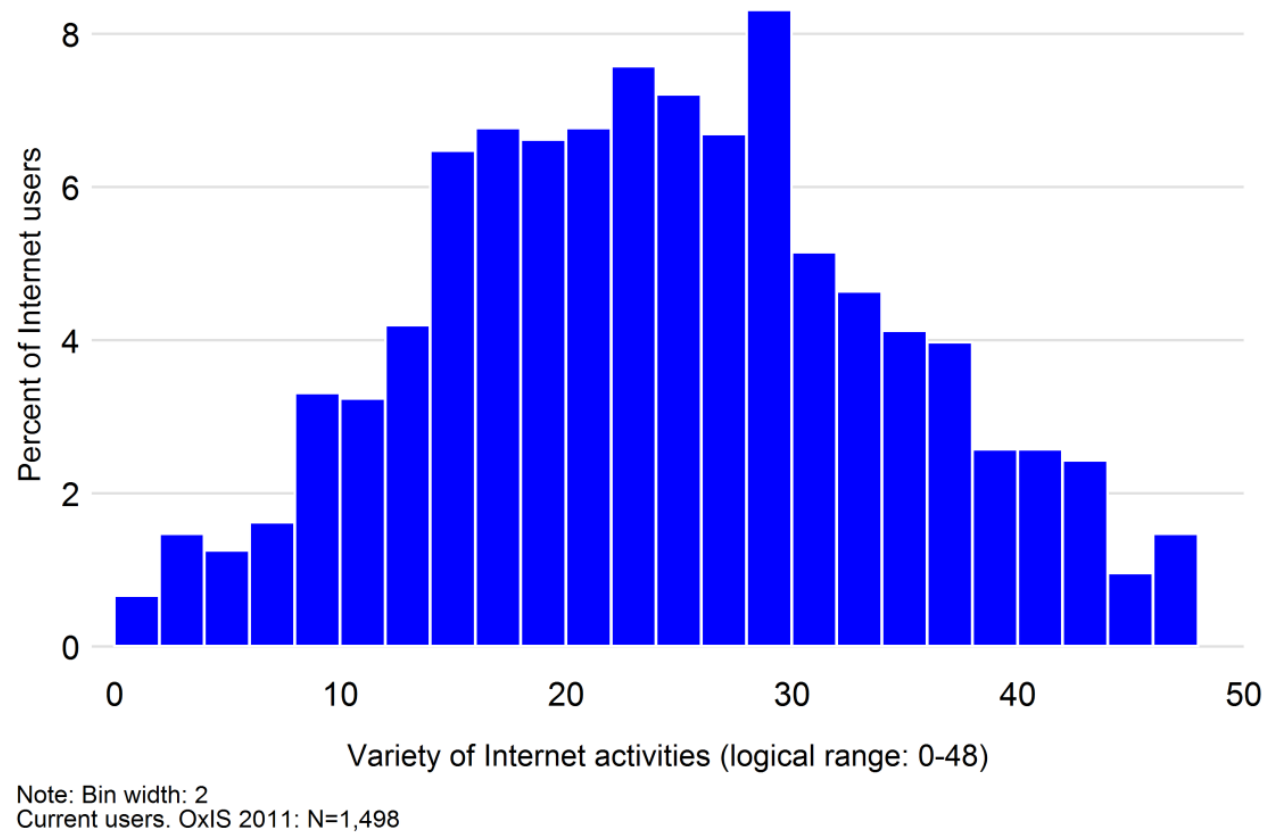

Figure 2 displays the distribution of amount of Internet use. It ranges from one to 180, with a mean of 56 and a median of 53 . The number is somewhat arbitrary since it is based on the sum of the Likert scales, but we can gain some feel for what it means if we divide the median amount, 53, by the median variety, 25 . This yields slightly over 2 . On the Likert scales 2 corresponds to an average frequency of use of "Monthly". The distribution of amount of use is largely symmetric with a slight left skew, but slightly less symmetric than variety of use (Figure 1). Like variety of use, the distribution of amount of use is also smooth and continuous with no natural breaks that would justify creation of multiple categories.

Figure 2: Amount of Internet Use 


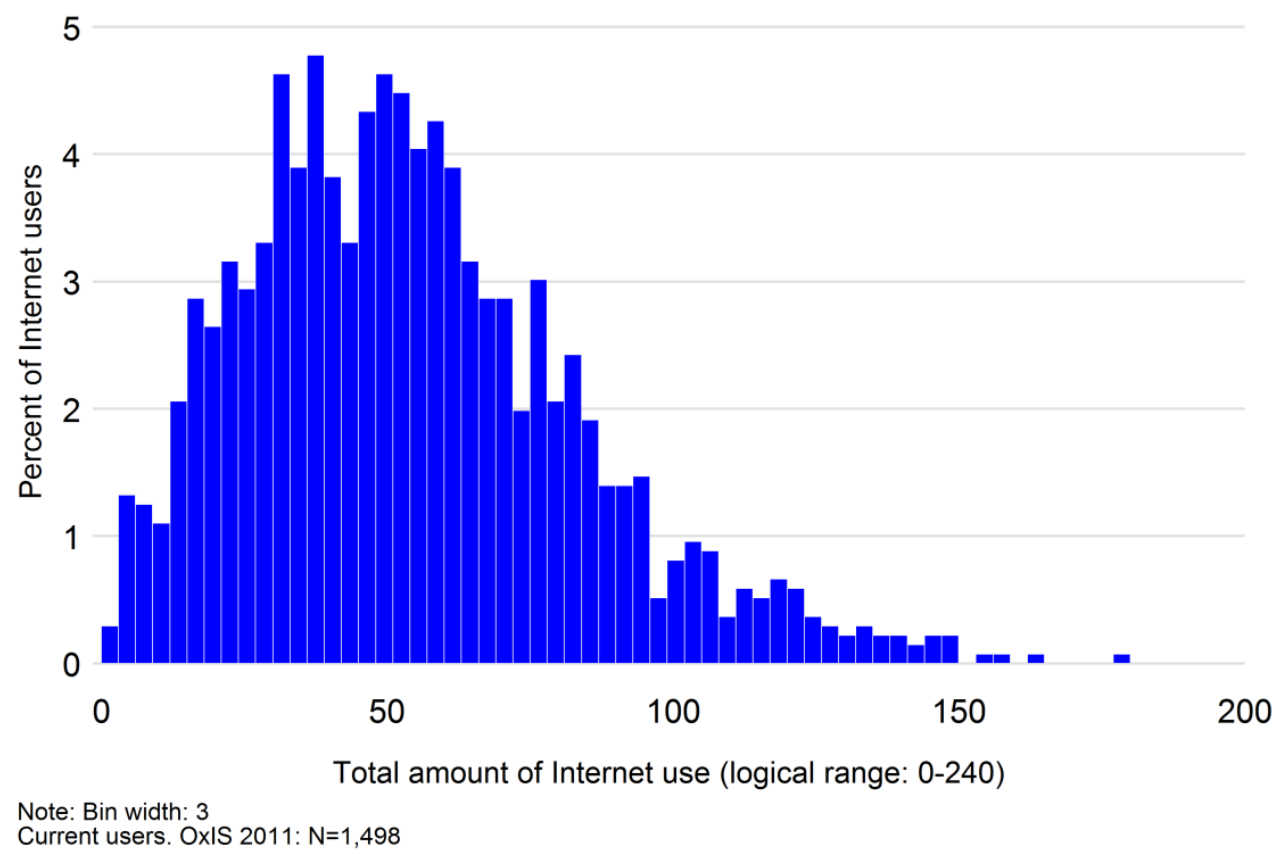

For the third dimension we want to find distinct types of online activities. We did principal components analysis (PCA) of the 48 activity variables ${ }^{4}$. After eliminating seven variables that did not load above 0.3 on any component, we used 41 variables in the final PCA. After varimax rotation and Kaiser normalization the result was that 10 components had eigenvalues greater than 1.0 , see Table 3 . The eigenvalues show that the variance is widespread among the 41 variables. The first component was dominated by watching movies and television, listening to music, and downloading and watching videos. All involve being entertained, so we named it entertainment. The second component involved buying, selling, comparing prices, making travel reservations, ordering groceries online and paying bills. Since all of these are commercial activities, we named this commerce. Loading on the third component are looking up facts or definitions and pursuing topics of interest. We named this information seeking. The fourth component is composed of instant messaging, chat, posting

\footnotetext{
${ }^{4}$ Our activity variables are ordinal; Kolenikov and Angeles (2004) found that ordinal variables work effectively in a PCA. Although we present results from Pearson product moment correlation coefficients we also tried Spearman rank order correlations with substantively identical results. We also did a cluster analysis which produced identical substantive results.
} 
photos, and maintaining a profile on a social network site. These are very social activities, and we named it socialising. The fifth component is dominated by email, use of attachments and distribution lists. All have email in common so we named it email.

The sixth through the $10^{\text {th }}$ components were named in similar ways. The sixth component involves reading and writing blogs, making Internet phone calls and maintaining a personal website. Blogs dominate so we named it blogging. The seventh component includes uploading videos or other files, looking for jokes and posting writing or anything 'creative'. These activities create content so we named it production. Loading on component eight are news, sports, and events. These are typical uses for traditional mass media, so we named it classic mass media. Component nine includes school- and work-related use of the Internet, so we named it school-work. Finally, the tenth component contains gambling and visiting adult, sex-related sites. We named it vice. 
Table 3: Internet Activity Types Factor Loadings from Principal Components Analysis

\begin{tabular}{|c|c|c|c|c|c|c|c|c|c|c|}
\hline Variable & $\begin{array}{l}\text { Enterta- } \\
\text { inment }\end{array}$ & $\begin{array}{l}\text { Comm- } \\
\text { erce }\end{array}$ & $\begin{array}{l}\text { Info } \\
\text { seeking }\end{array}$ & $\begin{array}{l}\text { Social- } \\
\text { ising }\end{array}$ & Email & Blog & $\begin{array}{l}\text { Produc- } \\
\text { tion }\end{array}$ & $\begin{array}{l}\text { Classic } \\
\text { Media }\end{array}$ & $\begin{array}{l}\text { School- } \\
\text { work }\end{array}$ & Vice \\
\hline Movies & 0.45 & & & & & & & & & \\
\hline TV & 0.44 & & & & & & & & & \\
\hline Dl music & 0.33 & & & & & & & & & \\
\hline Listen music & 0.36 & & & 0.17 & & & & & & \\
\hline Videos & 0.41 & & & & & & & & & \\
\hline Dl video & 0.34 & & & & & & 0.21 & & & \\
\hline Buy & & 0.39 & & & & & & & & \\
\hline Travel res & & 0.32 & & & & & & & & \\
\hline Pay bills & & 0.37 & & & 0.23 & & & & & \\
\hline Banking & & 0.32 & & & 0.25 & & & & & \\
\hline Compare & & 0.30 & 0.18 & & & & & & -0.24 & \\
\hline Food & & 0.39 & & & & & & & & \\
\hline Selling & & 0.39 & & & & & & & & \\
\hline Facts & & & 0.49 & & & & & & & \\
\hline Definitions & & & 0.48 & & & & & & & \\
\hline Topics & & & 0.44 & & & & & & & \\
\hline $\mathrm{IM}$ & & & & 0.45 & & & -0.18 & & & \\
\hline Chat & & & & 0.34 & & & & & & \\
\hline Photos & & & & 0.31 & & & 0.19 & & & \\
\hline SNS & & & & 0.52 & & & & & & \\
\hline Email & & & & 0.21 & 0.34 & & & & & \\
\hline Attach & & & & & 0.50 & & & & & \\
\hline List & & & & & 0.49 & & 0.27 & & & \\
\hline Phone & & & & -0.18 & 0.22 & 0.38 & & & & \\
\hline Read blog & & & & & & 0.47 & & & & \\
\hline Write blog & & & & & & 0.57 & & & & \\
\hline Website & & & -0.17 & 0.18 & & 0.38 & & & & \\
\hline Ul Video & & & & 0.21 & & & 0.44 & & & \\
\hline Ul creative & & & & & & 0.21 & 0.43 & -0.16 & & \\
\hline Jokes & & & & & & & 0.40 & 0.16 & & \\
\hline Ul files & 0.20 & & & & & & 0.35 & & & \\
\hline News & & & 0.18 & & & & & 0.36 & & \\
\hline Events & & & & & & & & 0.45 & & \\
\hline Sports & & & & & & & & 0.51 & & \\
\hline Travel plan & & 0.20 & & & & & & 0.35 & & \\
\hline Seek job & & & -0.19 & 0.18 & & & & 0.29 & 0.46 & \\
\hline School & & & 0.28 & & & & & & 0.45 & \\
\hline Work & & & & & 0.29 & & & & 0.34 & \\
\hline Distance learn & & & & & & & & & 0.51 & \\
\hline Gambling & & & & & & & & & & 0.70 \\
\hline Adult & & & & & & & & & & 0.67 \\
\hline $\begin{array}{l}\text { Eigenvalues } \\
\end{array}$ & 3.99 & 3.56 & 2.74 & 2.71 & 2.59 & 2.37 & 2.35 & 2.31 & 1.81 & 1.51 \\
\hline
\end{tabular}

Source: OxIS 2011, N=1,134 Internet users

Notes: Table contains sorted factor loadings after varimax rotation and Kaiser normalisation. "Dl" = Download; "Ul” = Upload; "SNS" = Social network site; "IM" = Instant messaging Loadings less than absolute value of 0.15 have been omitted. 
We can examine participation in these types of activities by creating new variables that measure participation. "Participation" is defined as doing the activities that load strongly on the component an average of more than Never; i.e. a " 1 ” or higher on the Likert scales. By this measure, email is the most common type: $93.5 \%$ of respondents email more than Never (see Table 4). Close behind is information seeking with over $85 \%$ participation, followed by classic mass media at $78 \%$ and socialising with over $61 \%$. At the lower end of the scale the eighth and ninth ranking types are associated with content creation and Web 2.0: blogging and production. This is consistent with other work, where more complex, difficult activities like blogging are less popular (e.g. Dutton \& Blank, 2011). The activity with least participation is vice, which remains a niche product. ${ }^{5}$

The Variety column in Table 4 shows the average variety of ten types for respondents who do each type. Thus, the first line says that people who email do an average of 4.1 types of use (including email). By comparison, people who do vice do an average of 5.8 types. Similarly, the Amount column shows the average amount of Internet use for respondents who do the specific use type. These numbers are based on the sum of the Likert scaled variables, so they are best used for comparison. Notice the inverse relationship between participation in type, and amount and variety of use. People who participate in the least popular activitiesvice, production and blogging — have both the highest variety and also the largest amount of use. This suggests that people who do niche activities are likely to be more active and do more things than people who do the popular activities.

\footnotetext{
${ }^{5}$ Vice activities are subject to social desirability effects. To minimize these they are not part of the regular interview, instead they are in an anonymous, self-completion questionnaire.
} 
Table 4: Participation in Types, Amount and Variety of Use

\begin{tabular}{llll} 
Activity & $\begin{array}{l}\text { Participation } \\
\text { (Percent) }\end{array}$ & $\begin{array}{l}\text { Amount } \\
\text { (mean) }\end{array}$ & $\begin{array}{l}\text { Variety } \\
\text { (mean) }\end{array}$ \\
\hline Email & 93.5 & 58.8 & 4.1 \\
Information seeking & 85.7 & 60.9 & 4.3 \\
Classic mass media & 78.3 & 63.3 & 4.6 \\
Socialising & 61.2 & 68.1 & 4.9 \\
Commerce & 59.8 & 68.2 & 4.9 \\
School and work & 48.1 & 72.4 & 5.3 \\
Entertainment & 46.3 & 75.6 & 4.5 \\
Blogging & 30.1 & 82.3 & 5.9 \\
Production & 23.4 & 87.3 & 6.3 \\
Vice & 20.9 & 73.7 & 5.8 \\
\hline
\end{tabular}

Source: OxIS $2011 \mathrm{~N}=1,498$ Internet users

Notes: "Participation" is percent who do the activity, on average, more than Never.

"Amount" is the mean amount of Internet use for respondents who participate in that activity (out of 240, see Figure 2).

"Variety" is the mean number of activity types for respondents who do the activity (out of the 10 possible types, see Table 3).

This suggests that amount and variety of use are positively related. When we plot them in Figure 3, we see a strong relationship: higher variety is closely associated with more use. Notice also that there are respondents at both extremes of the variety (x-) axis. Some people do all 10 activities, others do none at all. Remember that respondents who, on average, reported Never doing the activities on a component were coded as not having done that type; these are the zeros in the lower left corner. The strength of the association is striking. For example, except for the outlier, among people participating in 10 types, the person who has the least amount of Internet use still participates more than the person who has the most amount of Internet use among people participating in four types. 
Figure 3: Relation between Amount and Variety of Internet Use

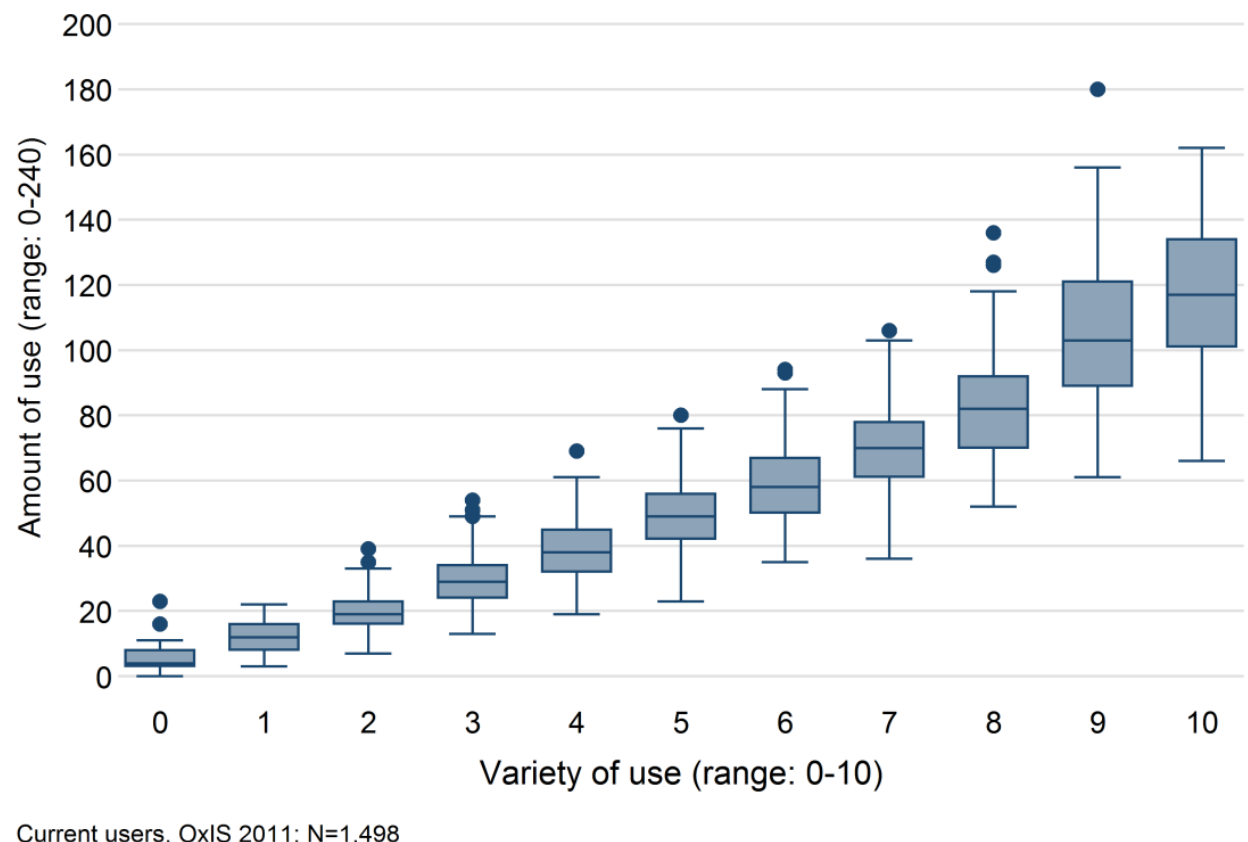

Finally, we can look at the characteristics of users of each type. Table 5 contains the results of OLS regressions using the factor scores from the PCA and total amount and variety of use as dependent variables. The predictors are seven demographic variables: age, gender, urban-rural, ethnicity, education, lifestage and marital status. 
Table 5: User Characteristics for Types, Amount, Variety of Use (Coefficients from OLS Regressions)

\begin{tabular}{|c|c|c|c|c|c|c|c|c|c|c|c|c|}
\hline Variable & $\begin{array}{l}\text { Enterta- } \\
\text { inment }\end{array}$ & Commerce & $\begin{array}{l}\text { Info } \\
\text { seeking }\end{array}$ & $\begin{array}{l}\text { Social- } \\
\text { ising }\end{array}$ & Email & Blog & $\begin{array}{l}\text { Produc- } \\
\text { tion }\end{array}$ & $\begin{array}{l}\text { Classic } \\
\text { media }\end{array}$ & $\begin{array}{l}\text { School- } \\
\text { work }\end{array}$ & Vice & $\begin{array}{l}\text { Amount } \\
\text { ( } \beta \text { coef. })\end{array}$ & $\begin{array}{l}\text { Variety } \\
(\beta \text { coef. })\end{array}$ \\
\hline Age & $-0.04 * * *$ & $-0.02 * * *$ & $-0.01^{*}$ & $-0.04 * * *$ & 0.00 & $-0.03 * * *$ & $-0.03 * * *$ & $-0.01^{* *}$ & $-0.02 * * *$ & $-0.01 * *$ & $-0.355^{* * *}$ & $-0.349 * * *$ \\
\hline Female & $-0.74 * * *$ & 0.00 & $-0.21^{*}$ & 0.09 & $-0.36 * * *$ & -0.16 & $-0.62 * * *$ & $-0.89 * * *$ & 0 & $-0.59 * * *$ & $-0.151^{* * *}$ & $-0.165^{* * *}$ \\
\hline Urban & 0.26 & -0.26 & -0.2 & 0.09 & 0.07 & 0.05 & $0.44 * * *$ & 0.17 & -0.05 & $0.26^{* *}$ & 0.02 & -0.002 \\
\hline Non-white & 0.21 & $-0.55^{* *}$ & 0.21 & -0.06 & $0.37 *$ & $0.82 * * *$ & -0.17 & 0.16 & 0.05 & -0.21 & 0.023 & 0.025 \\
\hline \multicolumn{13}{|l|}{ Education } \\
\hline Secondary & $0.52 * *$ & $0.65 * * *$ & $0.83 * * *$ & $0.46^{* *}$ & $0.55^{* * *}$ & -0.04 & 0.22 & $0.48^{* * *}$ & 0.23 & -0.07 & $0.162 * * *$ & $0.145^{* * *}$ \\
\hline Further & $1.13^{* * *}$ & $1.35^{* * *}$ & $1.32 * * *$ & $0.43^{* *}$ & $1.15^{* * *}$ & $0.43 *$ & 0.05 & $0.83^{* * *}$ & $0.50 * * *$ & -0.16 & $0.244 * * *$ & $0.219 * * *$ \\
\hline Higher & $0.86^{* * *}$ & $1.56^{* * *}$ & $1.83^{* * *}$ & $0.54 * * *$ & $1.66^{* * *}$ & $0.51^{* *}$ & $0.46^{* *}$ & $1.08^{* * *}$ & $0.87 * * *$ & -0.06 & $0.384 * * *$ & $0.370 * * *$ \\
\hline \multicolumn{13}{|l|}{ Lifestage } \\
\hline Employed & 0.12 & $1.50 * * *$ & $-0.46^{*}$ & $0.47 * *$ & $0.86^{* * *}$ & $0.51^{* *}$ & $0.50 * *$ & $0.91 * * *$ & $-0.37 *$ & $0.54 * * *$ & $0.121^{* *}$ & $0.129 * *$ \\
\hline Retired & 0.04 & $1.01 * *$ & $-0.60 *$ & 0.52 & -0.11 & $0.69 *$ & $0.54^{*}$ & $0.73 * *$ & $-0.86 * * *$ & $0.52 *$ & 0.023 & 0.034 \\
\hline Unemployed & -0.1 & $1.08 * * *$ & $-0.55^{* *}$ & $0.54 * *$ & 0.18 & 0.27 & $0.45 *$ & $0.66^{* * *}$ & $-0.39 *$ & $0.64 * * *$ & 0.015 & 0.016 \\
\hline \multicolumn{13}{|l|}{ Marital status } \\
\hline Married & $-0.79 * * *$ & $0.51^{* *}$ & 0.02 & $-0.72 * * *$ & 0.08 & -0.15 & $-0.57 * * *$ & -0.14 & -0.09 & $-0.29 * *$ & $-0.075^{*}$ & -0.049 \\
\hline Living w/ part & $-0.51 * *$ & 0.29 & -0.09 & $-0.43^{* *}$ & -0.01 & $-0.33^{*}$ & $-0.36^{*}$ & $-0.37 *$ & -0.12 & 0.08 & -0.037 & -0.017 \\
\hline Divorced & $-0.59 *$ & 0.1 & -0.06 & -0.33 & -0.17 & $-0.66^{* *}$ & -0.29 & $-0.46 *$ & 0.03 & 0.17 & -0.05 & -0.032 \\
\hline Widowed & -0.71 & 0.24 & 0.06 & -0.59 & 0.09 & 0.31 & -0.06 & -0.43 & 0.16 & -0.21 & -0.032 & -0.016 \\
\hline Constant & $1.42^{* * *}$ & $-1.39 * * *$ & 0.09 & $1.09 * * *$ & $-1.39 * * *$ & $0.62 *$ & $0.87 * * *$ & $-0.46 *$ & $0.72 * * *$ & 0.21 & - & - \\
\hline $\mathrm{N}$ & 1097 & 1097 & 1097 & 1097 & 1097 & 1097 & 1097 & 1097 & 1097 & 1097 & 1309 & 1309 \\
\hline Adjusted $\mathrm{R}^{2}$ & 0.25 & 0.17 & 0.16 & 0.25 & 0.23 & 0.12 & 0.20 & 0.18 & 0.16 & 0.10 & 0.27 & 0.24 \\
\hline
\end{tabular}

Notes: * $\mathrm{p}<.05 ; * * \mathrm{p}<.01 ; * * * \mathrm{p}<.001$; Source: OxIS 2011

Omitted categories are: male, rural, white, no degree, student, single 
Collectively, these regressions describe participants in most activities as young, welleducated and employed. The unique predictors of each activity type are our primary concern. Below we highlight what is unique in each regression.

- Entertainment: This is the only type of use where lifestage has no impact. Single individuals are more likely to use the Internet for entertainment than other marital status categories.

- Commerce: This is the only type of use where whites are more likely to be engaged in commerce than non-whites and married people more than single individuals. Gender did not impact the likelihood of online commercial activity.

- Information seeking: Students are more likely to use the Internet for information seeking than employed, retired, or unemployed people. Education has its strongest effect on information seeking behaviours but marital status has no effect whatsoever.

- Socialising: Gender does not influence the likelihood of socialising. Employed and unemployed people are more likely to use the Internet for socialising than students.

- Email: This is the only regression where age has no effect. There is also no effect for marital status. Non-whites are more likely to do email than whites and education has its second strongest effect.

- Blogging: Non-whites are more likely to blog than whites and employed and retired are more likely than students. Gender is not a significant predictor.

- Production: This is more likely among urban residents. Only higher education is a significant predictor of production.

- Classic mass media: This has the strongest gender effect. Students are more likely to use classic mass media than respondents who are divorced or living with a partner. 
- School and work: No marital status category has any significant effect and there is no gender effect. Students are more likely to use the Internet for school and work than any other lifestage.

- Vice: There is no significant education effect. This activity is more popular in urban areas. Only married people are more likely to do vice activities than singles.

The fundamental point of these regressions is that people with different characteristics do each type of activity. Even though there are only 14 independent variables (plus the constant) used to predict 10 types, no pairs of types overlap entirely. The statistically significant predictors of each type identify a unique group of people. This underscores the point that each of the 10 types is a separate dimension.

Finally, the right-most columns show regressions with amount and variety as dependent variables. Note that these columns report standardized regression coefficients. The message is simple and consistent across both variables: age and education matter, a lot. Gender also matters. Young, better educated and male Internet users are more likely exhibit higher amounts and varieties of use. Surprisingly, once other variables are controlled, employed tend to have both more Internet use and more varied use than students. The similarity of these two regressions corresponds to the strong relationship we saw in Figure 3. These results mirror other findings about the effects of demographic variables and, as such, are a useful confirmation of the validity of these measures. Finally, these results underscore the importance of research focusing on variations in Internet use patterns from the perspective of digital inequalities (Livingstone \& Helsper, 2007; van Dijk, 2013) and suggest that amount, variety and types are valid and important dimensions along which the patterns of use should be further examined. 


\section{DISCUSSION AND CONCLUSIONS}

This paper theorizes and empirically examines dimensions of Internet use with an aim of guiding future research into patterns of Internet use. Below, we discuss theoretical and empirical implications, as well as limitations of present research.

Previous studies lack analysis of the theoretical dimensions of Internet use. Most previous researchers have published without thinking about the dimensionality of their phenomenon, thus producing typologies that are conceptually incoherent. We argue that Internet use varies along multiple dimensions. At minimum we discuss three dimensions: amount, variety, and types. These three dimensions may not be an exhaustive classification. There is surely more work to do clarifying the dimensions of the property space. Future research could profitably focus on whether additional dimensions exist. For example, a possible additional dimension is Internet skills. Hargittai and Hsieh (2011) have published suggestive measures in this area. The property space of Internet use could also be extended by a dimension of physical access (DiMaggio, Hargittai, Celeste, \& Shafer, 2004; van Dijk, 2013), distinguishing various devices people use to go online, for example, by their degree of mobility.

Further theoretical development would benefit our understanding of separate dimensions and relations between them. For example, both the amount of use and variety of use shown in Figure 1 and Figure 2 have characteristics that seem not to have been noticed in prior research. The histograms show they have a relatively smooth distribution with a single mode. It is possible to divide either dimension into categories (e.g. Selwyn et al., 2005) but there are no gaps or other indications of "natural" divisions that suggest that categories can be empirically identified. Amount and variety are continuous variables. While there may be no natural categories, there is often practical value in using categories so that we can talk about "heavy" or "light" users. When we do this it is important to keep in mind that the researcher is creating something that does not exist empirically. Even if the researcher defines 
categories, it is important to recognise that they blend into each other without seams and without breaks in the distribution. Types, by contrast, are actually nominal categories. They are discrete entities. Unlike amount or variety of use they are not "more” or "less" than each other (although they can be ordered according to the proportion of respondents who do the activity, as we did in Table 4).

Finally, a normative lens could be applied to the study of types of use, as suggested in the digital divide literature (van Dijk, 2013; Zillien \& Hargittai, 2009). Some types of use could be preferred because they enhance social capital or other desirable characteristics (Wellman, Haase, Witte, \& Hampton, 2001).

To guide theoretical development, research into the Internet’s property space should include cross-dimensional analysis. This paper briefly described the relationship between type, amount and variety of uses, but much more can be done. The nature of that relationship-linear or curved, homoscedastic or heteroscedastic, possible ceiling or floor effects-and the strength of the relationship both deserve description. Is there a sequence of types that most people follow as they use the Internet more frequently? Does a certain variety of use always mean the same types? Or do different people with similar number of uses (variety) cluster around different types? These interesting questions would help theoretically reconcile various dimensions of Internet use.

This paper also has methodological implications. First, we present an alternative measure of the amount of Internet use, based on Internet activity variables, as opposed to a single-item measure often used in previous research (see discussion of Table 1). Although the cumulative measure of the amount of use does not have intuitive units, we believe it is a better representation of how people use the Internet, accounting for multitasking and habitual behaviours (Lindley, Meek, Sellen, \& Harper, 2012). Alternatively, amount of use could be 
measured in hours spent online, yet self-reported time use estimates are problematic in survey research (Greenberg et al., 2005).

Second, we operationalize participation in online activities (both, in single activities and in aggregated types) as more than Never. This measure can be problematic when generalizing across different activity types—while it is reasonable to expect that most people make travel reservations online less than monthly, use of email is likely to be more frequent. This brings us to a discussion of what respondents consider meaningful Internet use (Eynon \& Geniets, 2012). Researchers have usually assumed that they understood what is meaningful use, an assumption that is at least questionable. This deserves serious attention in future research.

Third, our analysis of types of use was based on a PCA to detect commonalities between different uses. This operated on variables. An alternative would be a PCA or cluster analysis of cases to classify users into groups sharing common attributes (see Table 1; e.g. Brandtzæg et al., 2011). While there is nothing intrinsically wrong with this approach, if the result is to be conceptually valuable then the variables must be conceptually homogeneous. Furthermore, all the standard statistical techniques used in this area, PCA, cluster analysis and descriptive statistics, as well as latent class analysis and latent profile analysis, share a similar weakness: they are sensitive to which variables are included. It is vital, therefore, to clarify which variables are important representatives of popular activities. Authors have worked with as few as 4 variables (e.g. Holmes, 2011), or have omitted variables measuring such key areas as classic media use (e.g. Brandtzæg et al., 2011; Heim \& Brandtzæg, 2007), which was the third most common activity in Britain in 2011 (see Table 4). This paper suggests at least 10 areas that should be covered in future research.

One important implication of the PCA in this paper is that it is possible to capture all of the ten activity types with many fewer than the 41 variables we used here. If a researcher used only the two variables that loaded strongest on each component in Table 3, all ten 
activity types could be measured with only 20 items. This is one methodological use of the current paper. It is clear, however, that we may not have measured all of the relevant activities. The 48 variables in OxIS do not exhaust all of the possible activities. For example, we included no variables measuring involvement with political processes or e-government activities, or items measuring specific activities on social network sites. Locating other activities and defining good measures is another promising area for future research.

Categories and items are crucial. As the Internet develops, it is likely that the common activities on the Internet will change. This suggests that longitudinal studies of changes in common activities could become one way to measure changes in the Internet. For example, some have suggested that social network site use has begun to supplant email, at least for some people. While we see no actual evidence of this in longitudinal analyses of email use (e.g. Dutton \& Blank, 2011), it is certainly possible that some Internet activities may compete with other activities. As the Internet changes, activities may wax and wane in popularity for many reasons. Longitudinal studies of changes in Internet activities can be one way to measure the changing impact of the Internet.

Finally, the results of the present study have implications for digital divide research. Studies of the relation between inequality and differences in Internet use are emerging (e.g. van Deursen \& van Dijk, 2013; Zillien \& Hargittai, 2009). Those studies show important differences in types of Internet activity based on social status (Blank, 2013). An important first step is identifying and describing all dimensions along which Internet use can vary. We believe the present paper makes a significant contribution to identifying dimensions of Internet use that deserve further research from the digital inequalities perspective.

The distinction between amount, variety and types is fundamental. It is a theoretical distinction that influences which variables are measured, how they are measured, how they are analysed and how the analysis is interpreted. It has to be built into research at the design stage. 


\section{BIBLIOGRAPHY}

Barton, A. H. (1955). The concept of property-space in social research. In P. F. Lazarsfeld \& M. Rosenberg (Eds.), The Language of social research: a reader in the methodology of social research (pp. 40-53). Glencoe, IL: Free Press.

Blank, G. (2013). Who Creates Content? Stratification and content creation on the Internet. Information, Communication \& Society, 16(4), 590-612. doi:10.1080/1369118X.2013.777758

Brandtzæg, P. B. (2010). Towards a unified Media-User Typology (MUT): A meta-analysis and review of the research literature on media-user typologies. Computers in Human Behavior, 26(5), 940956. doi:10.1016/j.chb.2010.02.008

Brandtzæg, P. B., Heim, J., \& Karahasanović, A. (2011). Understanding the new digital divide-A typology of Internet users in Europe. International Journal of Human-Computer Studies, 69(3), 123-138. doi:10.1016/j.ijhcs.2010.11.004

DiMaggio, P., Hargittai, E., Celeste, C., \& Shafer, S. (2004). Digital Inequality: From Unequal Access to Differentiated Use. In K. Neckerman (Ed.), Social Inequality (pp. 355-400). Russell Sage Foundation.

Dutton, W. H., \& Blank, G. (2011). Next Generation Users: The Internet in Britain. Oxford: Oxford Internet Institute. Retrieved from http://oxis.oii.ox.ac.uk/reports

Eynon, R., \& Geniets, A. (2012). On the Periphery? Understanding Low and Discontinued Internet Use Amongst Young People in Britain - Report for the Nominet Trust. Oxford: Oxford Internet Institute. Retrieved from http://www.oii.ox.ac.uk/research/projects/?id=87

Eynon, R., \& Malmberg, L.-E. (2011). A typology of young people's Internet use: Implications for education. Computers \& Education, 56(3), 585-595. doi:10.1016/j.compedu.2010.09.020

Greenberg, B. S., Eastin, M. S., Skalski, P., Cooper, L., Levy, M., \& Lachlan, K. (2005). Comparing Survey and Diary Measures of Internet and Traditional Media Use. Communication Reports, 18(1-2), 1-8. doi:10.1080/08934210500084164

Hargittai, E., \& Hsieh, Y. P. (2011). Succinct Survey Measures of Web-Use Skills. Social Science Computer Review, 30(1), 95-107. doi:10.1177/0894439310397146

Heim, J., \& Brandtzæg, P. B. (2007). Patterns of media usage and the non-professional users. In CHI '07, the SIGCHI Conference on Human factors in computing systems (pp. 1-6). San Jose, CA, USA.

Holmes, J. (2011). Cyberkids or divided generations? Characterising young people's internet use in the UK with generic, continuum or typological models. New Media \& Society, 13(7), 11041122. doi:10.1177/1461444810397649

Horrigan, J. B. (2007). A Typology of Information and Communication Technology Users. Washington, D.C.: Pew Research Center's Internet \& American Life Project. Retrieved from http://www.pewinternet.org/Reports/2007/A-Typology-of-Information-and-CommunicationTechnology-Users.aspx

Howard, P. E. N., Rainie, L., \& Jones, S. (2001). Days and Nights on the Internet: The Impact of a Diffusing Technology. American Behavioral Scientist, 45(3), 383-404. doi:10.1177/0002764201045003003

Kolenikov, S., \& Angeles, G. (2004). The Use of Discrete Data in PCA: Theory, Simulations, and Applications to Socioeconomic Indices. University of North Carolina, Chapel Hill. Retrieved from http://www.cpc.unc.edu/measure/publications/wp-04-85 
Lindley, S., Meek, S., Sellen, A., \& Harper, R. (2012). "It's Simply Integral to What I do": Enquiries into how the Web is Weaved into Everyday Life. In WWW '12 Proceedings of the 21st international conference on World Wide Web (pp. 1067-1076). Lyon, France. doi:10.1145/2187836.2187979

Livingstone, S., \& Helsper, E. (2007). Gradations in digital inclusion: children, young people and the digital divide. New Media \& Society, 9(4), 671-696. doi:10.1177/1461444807080335

Ortega Egea, J. M., Recio Menéndez, M., \& Román González, M. V. (2007). Diffusion and usage patterns of Internet services in the European Union. Information Research, 12(2), Paper 302. doi:InformationR.net/ir/12-2/paper302.html]

Ruggiero, T. E. (2000). Uses and Gratifications Theory in the 21st Century. Mass Communication and Society, 3(1), 3-37. doi:10.1207/S15327825MCS0301_02

Selwyn, N., Gorard, S., \& Furlong, J. (2005). Whose Internet is it Anyway?: Exploring Adults' (Non)Use of the Internet in Everyday Life. European Journal of Communication, 20(1), 5-26. doi:10.1177/0267323105049631

van Deursen, A. J., \& van Dijk, J. A. (2013). The digital divide shifts to differences in usage. New Media \& Society. doi:10.1177/1461444813487959

van Dijk, J. A. (2013). A theory of the digital divide. In M. Ragnedda \& G. W. Muschert (Eds.), The Digital Divide: The internet and social inequality in international perspective (pp. 29-51). Abingdon: Routledge.

Wellman, B., Haase, A. Q., Witte, J., \& Hampton, K. (2001). Does the Internet Increase, Decrease, or Supplement Social Capital? Social Networks, Participation, and Community Commitment. American Behavioral Scientist, 45(3), 436-455. doi:10.1177/00027640121957286

Zillien, N., \& Hargittai, E. (2009). Digital Distinction: Status-Specific Internet Uses. Social Science Quarterly, 90(2), 274-291. doi:10.1111/j.1540-6237.2009.00617.x 